\title{
The effect of sub-grid rainfall variability on the water balance and flux exchange processes resolved at climate scale: the European region contrasted to Central Africa and Amazon rainforests
}

\author{
D. Wang, E. N. Anagnostou, and G. Wang \\ Department of Civil and Environmental Engineering, University of Connecticut, Storrs, Connecticut, USA \\ Received: 28 October 2005 - Revised: 15 March 2006 - Accepted: 16 March 2006 - Published: 10 April 2006
}

\begin{abstract}
This paper investigates the effect of sub-grid rainfall variability on the simulation of land surface hydrologic processes of three regions (Europe, Africa and Amazon) with contrasting precipitation and vegetation characteristics. The sub-grid rainfall variability is defined in terms of the rainfall coverage fraction at the model's grid cells, and the statistical distribution of rain rates within the rain-covered areas. A statistical-dynamic approach is devised to incorporate the above variability properties into the canopy interception process of a land surface model. Our results reveal that incorporation of sub-grid rainfall variability significantly impacts the land-atmosphere water vapor exchanges. Specifically, it alters the partitioning between runoff and total evapotranspiration as well as the partitioning among the three components of evapotranspiration (canopy interception loss, ground evaporation and plant transpiration). This further influences the soil water, and to a lesser effect surface/vegetation temperatures and surface heat fluxes. It is shown that, overall, rainfall variability exerts less of an impact on the land-atmosphere flux exchanges over Europe compared to Africa and Amazon.
\end{abstract}

\section{Introduction}

Precipitation is arguably the most important component of the land-atmospheric system accountable for shaping the climatic state and variability of water in the soil and atmosphere. Understanding the fate of precipitation as soil moisture, snowpack, evapo-transpiration and runoff is the key to capturing the global make-up of surface hydrology. Currently, precipitation derived from coupled global climate models is not sufficient to accurately characterize the water and energy exchanges in global land-atmospheric processes. This problem stems from the fact that climate model grid resolution is coarser than the resolution required to model

Correspondence to: E. N. Anagnostou

(manos@engr.uconn.edu) land surface processes. Another issue is the scale mismatch between the size of a typical rain cell and that of a climate model grid cell. As an effect the atmospheric model used in coupled land-atmospheric systems would provide as input to the land surface model a grid-average rainfall, which is associated with highly underestimated rainfall intensity since it represents rainfall uniformly falling over the entire grid cell and the entire model time step, instead of the rather intense rainfall concentrated over a smaller fraction of the grid cell and portion of model's time step duration.

For any given land surface condition, rainfall characteristics (rainfall intensity in particular) is the utmost important factor controlling water partitioning at the land surface between evapotranspiration and runoff as well as the partitioning of total evapotranspiration among canopy interception loss, plant transpiration, and soil evaporation. Over vegetated land, a major fraction of the water from drizzle-type rainfall tends to stay on the vegetation canopy and subsequently evaporate, becoming canopy interception loss. This fraction is smaller for low intensity stratiform-type rainfall, while in the case of convective storms the canopy interception loss is minimal. Correspondingly, canopy throughfall as well as runoff ratio is very small (if not zero) in drizzle events, a little larger in low intensity widespread events, and much larger for intense (convective) rainfall. Therefore, in order to accurately simulate the surface hydrological processes and landatmosphere interactions, coupled models need not only be accurate in terms of mean rainfall amounts, but also generate realistic values of the fine scale rainfall rates. The latter remains a challenge to all existing global climate models, which due to coarse resolution cannot resolve the variability of rainfall at small spatial and temporal scales.

To obtain a more realistic forcing to drive land surface processes, it is necessary that coupled models include some form of representation for the sub-grid variability of rainfall. One way to address this problem is by explicitly dividing grid cells of the model into a certain number of sub cells and disaggregating rainfall among the sub cells (e.g., Avissar and Pielke, 1989; Ghan et al., 1997). The computational 
expense incurred by the explicit disaggregation approach increases quickly with the number of sub cells, which currently limits its application in global models. An alternative approach (named statistical-dynamic approach, SDA) is to combine the point description of land surface hydrologic processes with a statistical treatment of rainfall sub-grid variability (Shuttleworth, 1988; Wang and Eltahir, 2000). SDA assumes that the model-generated rainfall only falls over a fraction, $\mu$, of the model grid cell and that within this fraction, rainfall is assumed to follow a known marginal distribution $(p d f)$. Investigators have argued that parameter $\mu$ can be climatologically represented by the ratio of model predicted rainfall to the intensity inferred from observations (Eltahir and Bras, 1993; Wang and Eltahir, 2000). This approach allows for temporal and spatial variations of $\mu$ and accounts for model dependences. Nevertheless, its application relies on the availability of global high-resolution rainfall data to acquire seasonal and regional estimates of $\mu$ and rain rate $p d f$ parameters.

Global high-resolution rainfall observations are currently available based on passive microwave sensors onboard a number of earth-orbiting platforms such as the Special Sensor Microwave/Imager (SSM/I) instrument on the Defense Meteorological Satellite Program satellites, the Advance Microwave Scanning Radiometer aboard EOS-AQUA satellite, and the Microwave Imager (TMI) aboard TRMM satellite. TRMM also carries the first space based Precipitation Radar providing the most accurate overland rainfall estimates currently available from space (e.g., Kummerow et al., 2000; Grecu and Anagnostou, 2002). Multi-year data from the above sensors can be used to obtain $\mu$ and $p d f$ parameters for use in global climate models. In a recent study, Wang et al. (2005) demonstrated the concept over Africa and South America (Amazon basin) based on three years of highresolution TMI-derived rainfall datasets.

In this paper, we build upon Wang et al. (2005) scheme to evaluate the relative significance of sub-grid rainfall variability on water balance and flux exchange processes resolved by a land surface model at regional scale. The study focuses in three vegetation distinct regions: the Central-South Europe and the tropical rainforests of central Africa (Congo basin) and the Amazon basin. It is based on land surface simulation experiments as described in the following Sect. 2. In Sect. 3 we present and analyze results, and we close in Sect. 4 offering our conclusions and discussion on future research.

\section{The experiment}

A land surface simulation experiment is formulated in this study to investigate the effects of sub-grid rainfall variability on canopy interception and consequentially on other land surface hydrological processes resolved at regional to global scale ( $>1$ deg grid resolution). The Community Land Model (CLM - Dai et al., 2003) in a stand-alone mode forced by NCEP/NCAR reanalysis data (Kalnay et al., 1996) is used to simulate land surface hydrological processes. The very issue of simple representation of canopy interception arises from the coarse resolution of surface forcing in coupled landatmosphere simulations. In using the stand-alone version of CLM, the reanalysis data is used as a surrogate for the atmospheric model-simulated forcing. Ultimate goal is to build a strong basis for representing rainfall variability in couple land-atmospheric systems where the effect in land surface processes would feedback to altering atmospheric model simulations (e.g., clouds and precipitation) with culminating effects on the predicted water and energy cycle.

CLM is one-dimensional physically based land surface model developed and supported by an International group of scientists. It can be used either as a land surface parameterization in coupled models, or in stand-alone mode for simulating land surface processes. A set of parameters that specify physical constants and aspects of the soil and vegetation distribution are used to control the simulated processes. Physically-based parameterizations of water and energy fluxes are used to describe soil-vegetation-atmosphere interactions and remotely sensed soil and vegetation characteristics is used to specify the nature of the ground surface in the numerical model. Given as input meteorological forcing variables the model provides prognostic and diagnostic land surface state variables and surface energy and water fluxes as output.

To investigate the effects of rainfall variability on land surface hydrological processes, two types of model simulations (Control and Experiment) are designed. Control simulations use the default canopy interception scheme of CLM, which estimates the canopy inception according to Eq. (1):

$I_{c}=P_{m}[1-\exp (-0.5(L A I+S A I))]$

where $P_{m}$ is the grid-averaged rainfall intensity (simulated by atmosphere models; here derived from the reanalysis data), $L A I$ is one-sided leaf area index, and $S A I$ is one-sided stem area index. Both $L A I$ and $S A I$ parameters are variable in space and time. Like in most climate models, vegetation properties (e.g., $L A I)$ were derived from AVHRR NDVI data. The quality of AVHRR data has been questioned due to factors such as satellite drift and changeover. In our study, we have used $L A I$ derived from MODIS observations (Tian et al., 2004), which is of superior quality compared with AVHRR data.

With the default scheme, the canopy interception is not related to the sub-grid rainfall variability. It is solely controlled by the grid-averaged rainfall intensity. Experiment simulations were then devised to account for the impact of rainfall sub-grid variability on canopy interception on the basis of Eq. (2) (Shuttleworth, 1988):

$I_{c}^{\bmod }=P_{m}-\mu \int_{I_{\max }}^{\infty}\left(P-I_{\max }\right) f(P) d P$

In Eq. (2) $\mu$ represents the rainfall coverage fraction and $f(P)$ is the probability density function $(p d f)$ of fine scale rain rates, $P$. Both parameters are considered to vary by region and season. Parameter $I_{\max }$ is the maximum canopy interception rate $\left(I_{\max }=\frac{C-S}{\Delta t}\right)$, where $S$ is the canopy storage, 
(a) Runoff ratio

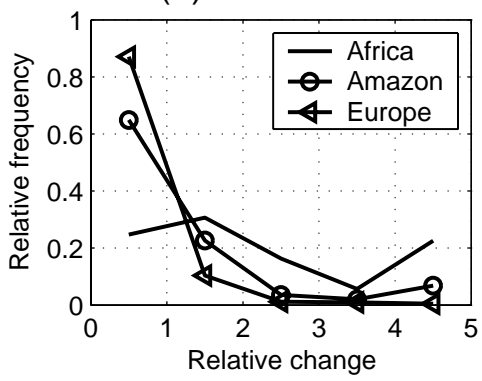

(b) Evapotranspiration ratio

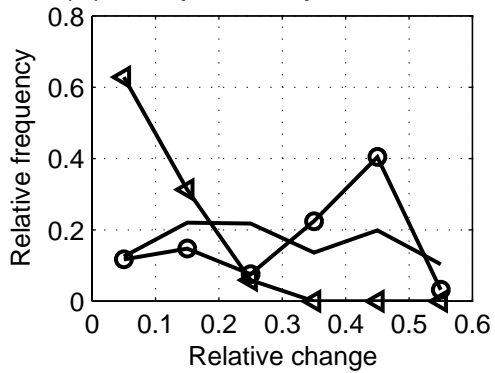

(c) Interception loss ratio

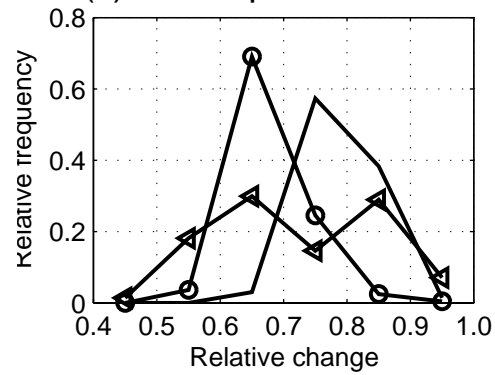

(d) Ground evaporation ratio

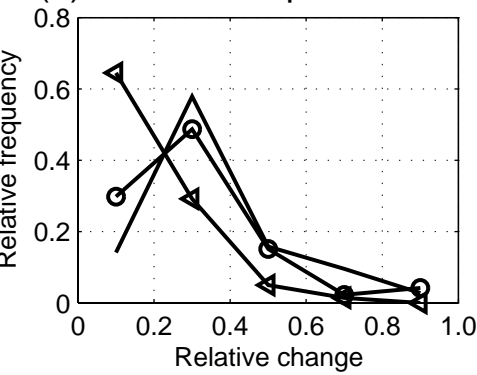

(e) Plant Transpiration ratio

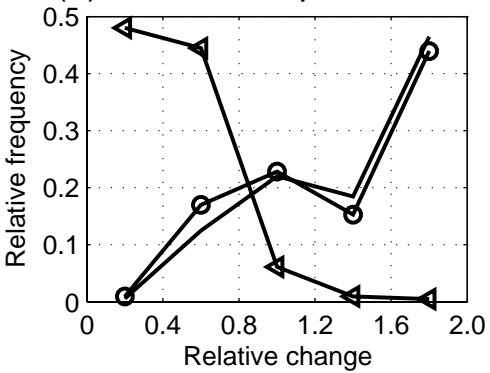

Fig. 1. Relative changes in runoff, evapotranspiration, interception loss, ground evaporation and plant transpiration over Africa, Amazon and Europe.

$C$ is the canopy water storing capacity and proportional to the sum of leaf area index $(L A I)$ and stem area index $(S A I)$, and $\Delta t$ is the model time step. The canopy water storing capacity is related to leaf and stem area index of canopy, while $S$ is determined through the model's vegetation water balance equation.

Parameters $\mu$ and $f(P)$ in this study were determined for three distinct regions on earth (Europe, Central Africa and the Amazon basin) on the basis of high-resolution data of rainfall intensity. The rainfall dataset was based on multiyear (2001-2003) overland rain estimates at 0.1-deg resolution from combination of SSM/I and TMI observations (Dinku and Anagnostou, 2005a, b). The conditional mean $(\mathrm{P}>0)$ of rain rates was calculated for each month and onedegree grid cells. The rainfall coverage fraction $\mu$ was then calculated taking the ratio of modeled grid-averaged rainfall intensity to the corresponding observation-based conditional mean rain rate. This approach ensures that surface rainfall predicted by the model is delivered to the surface at the observed sub-grid variability. Since the conditional mean rainfall intensities are obtained for the different months and each grid cell, $\mu$ values from this approach captures the spatial and seasonal variability of rainfall. The rainfall $p d f \mathrm{~s}$ were determined from the satellite data for the three climate regimes (Europe, Africa and Amazon) and each month separately.

The determined $\mu$ and $p d f$ values were used in Eq. (2) to modify the interception processes of CLM in the Experiment simulations. In both the Control and Experiment simulations, the time step was set to one hour. To obtain the initial val- ues of model state variable (e.g., vegetation temperature, soil temperature, and soil moisture), five years of spinup was conducted before running the model. To represent a 5-year spinning up, the model was cycled five times through the same atmospheric forcing and boundary conditions. Furthermore, to make the initial conditions consistent with model simulations, we used the default and modified interception schemes in the spinups of the control and the experiment runs, respectively. The simulation period used in this study spans from 1 January to 31 December 2001. Results are discussed next.

\section{Results and discussion}

To compare the effect of the rainfall subgrid variability on the hydrological processes among these three regions (CentralSouth Europe, central Africa and the Amazon basin), we focus our study on the water balance, soil moisture, and surface/vegetation temperature parameters. The relative change (RC), defined as the absolute difference in a hydrological variable $(V)$ between the Control simulation (labeled as CTL) and the Experiment simulation (labeled as EXP) normalized by the Control simulation of the variable, is used as the criterion for assessing the effect:

$R C=\frac{\left|V_{E X P}-V_{C T L}\right|}{V_{C T L}}$

Figure 1 shows the relative changes of runoff, evapotranspiration, interception loss, ground evaporation and plant transpiration ratios over these three regions. The impact of 
(a) Africa

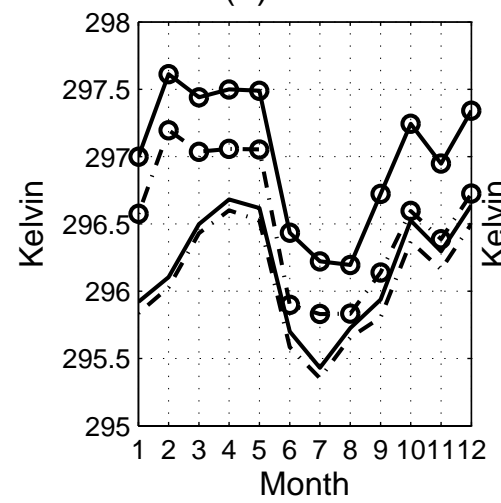

(b) Africa

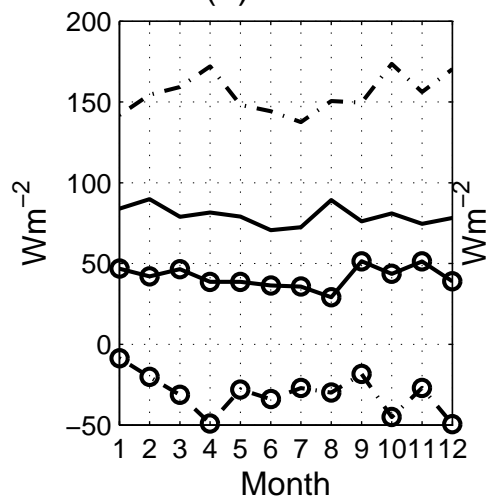

(c) Amazon

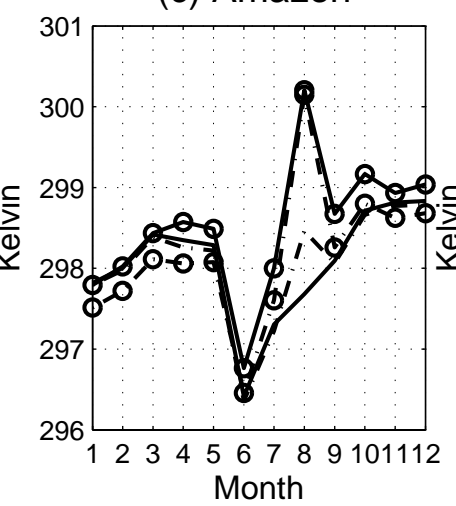

(d) Amazon

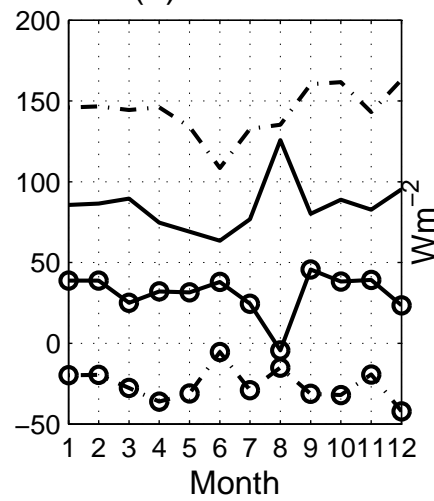

(e) Europe

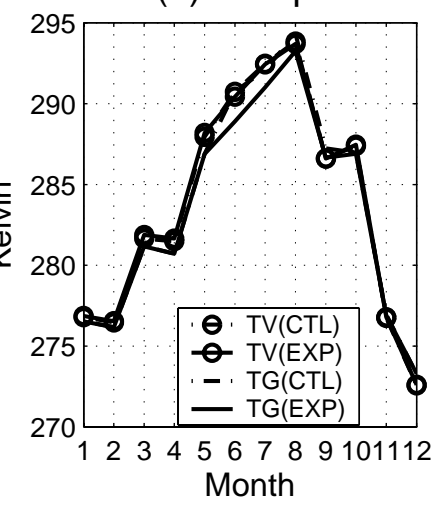

(f) Europe

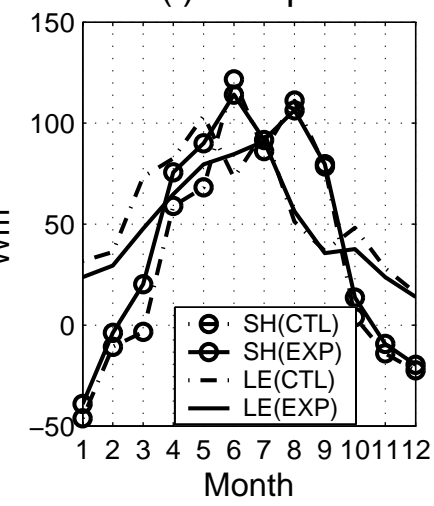

Fig. 2. Seasonal cycles of vegetation/ground temperatures (upper panels) and sensible and latent heat fluxes (lower panels) for the selected sites in Africa, Amazon and Europe. TV, TG, SH, and LE stand for vegetation temperature, ground temperature, sensible heat flux, and latent heat flux, respectively.

rainfall subgrid variability on the hydrological cycle starts with the canopy interception processes. The difference in the intercepted water by canopy between CTL and EXP depends on the rainfall coverage fraction $\mu$ and the leaf area index (LAI) as the evident from Eqs. (1) and (2). As analyzed in Wang et al. (2005), the difference in canopy interception between CTL and EXP decreases as $\mu$ increases and increases with the increase of $L A I$. Since the interception loss largely relies on available water on the vegetation canopy, the fraction $\mu$ and $L A I$ are two dominant factors causing the difference therefore the relative change. $L A I$ over Europe is much smaller than that either in Africa or Amazon, which causes a smaller RC. On the other hand, the rainfall coverage fraction $\mu$ over Europe is comparable with that over Africa, which is smaller than in the Amazon causing larger RC. The mean RC of interception loss ratio over Europe is 0.72, which is in between the corresponding values in Africa (0.79) and Amazon (0.68). The RC of plant transpiration ratio differs among different regions mainly due to the difference in LAI. Because of the lowest vegetation density over Europe, the RC of plant transpiration ratio over this region is smallest with a mean relative change of 0.44 compared to 1.75 in Africa and 2.44 in Amazon. The RC of ground evaporation ratio is the smallest over Europe. Because the total evapotranspiration is the sum of interception loss, plant transpiration and ground evaporation, the rainfall subgrid variability exert less significant impact on the amount of total evapotranspiration over Europe than over Africa or Amazon.

Independent observations of the interception loss from the Amazon rainforest and the southwest Mediterranean region are used to provide insights as to which experiment (CTL vs. EXP) is closest to reality. Specifically, from a two-year measurement database at Ducke Reserve $\left(2.95^{\circ} \mathrm{S}, 59.95^{\circ} \mathrm{W}\right)$, the annual interception loss ratio in the Amazon tropical forest area was found to be 0.124 (Shuttleworth, 1988). The simulated annual interception loss ratios at the closest model grid site $\left(2.5^{\circ} \mathrm{S}, 59.5^{\circ} \mathrm{W}\right)$ are 0.476 and 0.177 for CTL and EXP scenarios, respectively. As noted by the above comparison, EXP scenario is much closer to the observations than CTL. For the Mediterranean region, the modeled annual interception loss ratio in the EXP scenario is 0.152 at the $\left(42.5^{\circ} \mathrm{N}\right.$, $\left.1.5^{\circ} \mathrm{E}\right)$ model grid site, which is close to the mean interception loss value (0.174) observed at Cal Parisa Basin $\left(42.2^{\circ} \mathrm{N}\right.$, $1.8176^{\circ} \mathrm{E}$ ) (Llorens et al., 1997). In contrast, the corresponding value in CTL simulation is 0.446 , which diverges significantly from observations.

The change of water balance caused by the rainfall subgrid variability leads to changes in heat fluxes and temperatures. 
(a) Africa

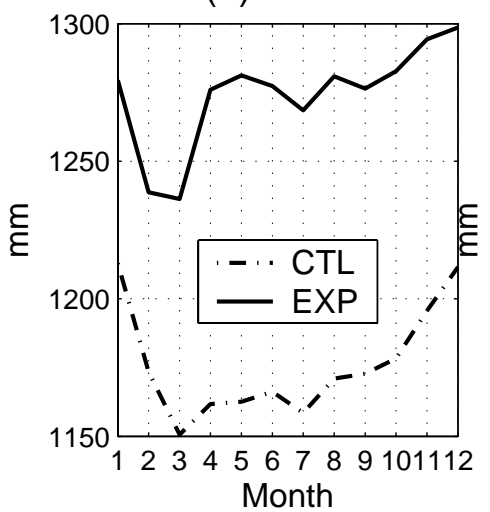

(b) Africa

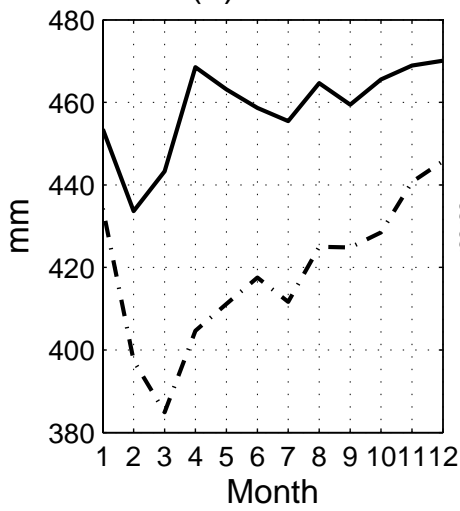

(c) Amazon

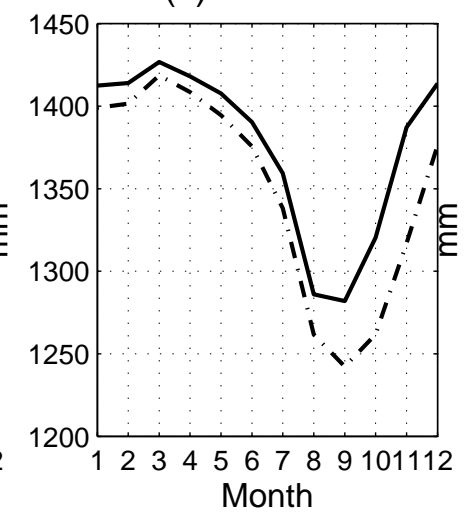

(d) Amazon

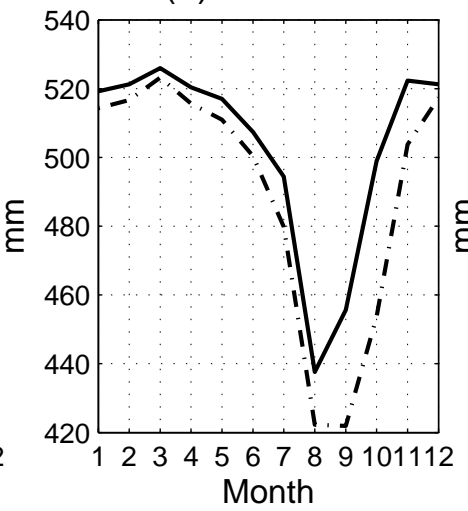

(e) Europe

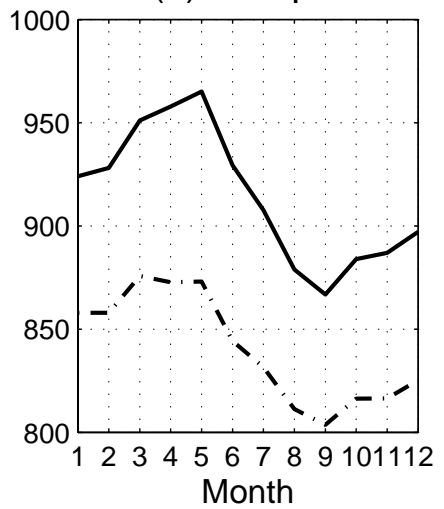

(f) Europe

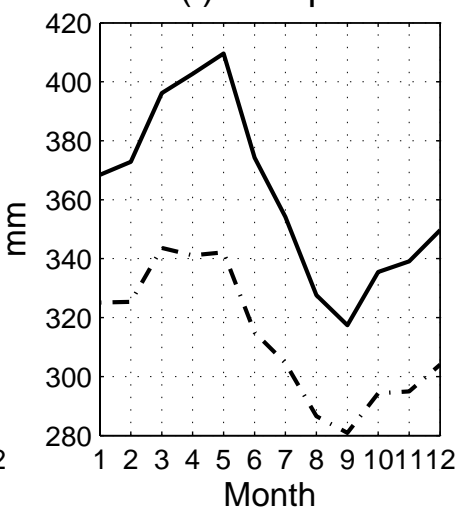

Fig. 3. Seasonal cycles of soil water within the 10 layers totaling $3.44 \mathrm{~m}$ (upper panels) and soil water within the top 1-m (lower panels) for the selected sites in Africa, Amazon and Europe.

Figure 2 shows the seasonal cycles of sensible and latent heat fluxes and surface and vegetation temperatures in CTL and EXP at a typical site of the three regions: site at $\left(23.5^{\circ} \mathrm{E}\right.$, $\left.2.5^{\circ} \mathrm{S}\right)$ with $L A I$ of 5.4 in Africa, site at $\left(65.5^{\circ} \mathrm{W}, 7.5^{\circ} \mathrm{S}\right)$ with $L A I$ of 5.4 in Amazon, and site at $\left(4.5^{\circ} \mathrm{E}, 45.5^{\circ} \mathrm{N}\right)$ with $L A I$ of 3.0 in Europe. Generally, the rainfall subgrid variability impact the seasonal cycles of heat fluxes more significantly than those of temperatures. Latent heat flux increases by about $20 \mathrm{Wm}^{-2}$ over Europe due to the rainfall subgrid variability. This is a significant increase, even though it is smaller than over Africa or Amazon regions where the increase reaches $50-80 \mathrm{Wm}^{-2}$ for most of the seasons. The rainfall subgrid variability causes little change in both the seasonal cycles and magnitudes of ground/vegetation temperatures over these three regions, except in the African region the latent heat flux increases by about $0.5^{\circ} \mathrm{C}$ from $\mathrm{CTL}$ to EXP.

Figure 3 shows the seasonal cycles of soil water within the 10 layers (totaling $3.44 \mathrm{~m}$ ) and within the top 1 meter for the same sites used in Fig. 2. Soil water within the 10 layers increases by about $90 \mathrm{~mm}$ in most seasons over Europe when the rainfall variability is included, which is comparable to that over Africa (90-120 mm increase). The effect of the variability on the soil water over Amazon is not as signif- icant. For the soil water within the top 1-m, it increases by 30-70 mm from CTL to EXP over Europe, which is similar to that over Amazon in terms of magnitude. Again, the rainfall subgrid variability does not exhibit significantly impact on the 1-m soil water of the Amazon region.

\section{Conclusions and future research}

In this paper, we used a multi-year (2001-2003) passive microwave rainfall dataset to examine the implication of representing sub-grid rain variability in the land surface component of climate models. The rainfall data are retrieved from a combination of SSM/I and TMI observations. The study is conducted over three regions (Africa, Amazon and Europe) with contrasting precipitation and vegetation characteristics. Comparing the results from the control runs with those from the experiment runs (that include the rainfall sub-grid variability) we found that including rainfall variability alters the water balance, favoring more transpiration (and ground evaporation) and significantly less interception loss. The effect on the interception loss ratio is the greatest among all the hydrological variables. The impact of rainfall sub-grid variability on land surface hydrological processes is shown to be consistent among the three regions, but with differences in 
terms of magnitude. These differences may have risen from differences in $L A I$ and spatial variation in the rainfall coverage fraction. Specifically, due to the smaller $L A I$ values over Europe the rainfall variability exerts less of an impact on the water balance, heat fluxes and ground/vegetation temperatures compared to Africa and Amazon. However, in the case of soil moisture, rainfall variability has an important effect over Europe, which is shown to be even more significant than that over Amazon.

Results of this study are limited in the sense that the rainfall variability impact on hydrological processes was determined using a stand-alone land surface model. Since the land surface interacts with the atmosphere through a coupled system, such an impact is expected to propagate into the atmospheric hydrological cycle, and further influence the surface hydrological processes through positive feedbacks (Wang and Eltahir, 2000). We are currently working on investigating this issue using coupled land surface-vegetationatmosphere models. Such study will help us assess the impact of rainfall sub-grid variability on the full water cycle through interactions between land surface and the overlying atmosphere.

Acknowledgements. This study was supported by NASA's Global Water and Energy Cycle Program (NAG5-11527) (to E. N. Anagnostou) and by NOAA GEWEX Americas Prediction Project (NA030AR4310080) (to G. Wang). D. Wang is supported by a NASA Earth System Science Fellowship.

Edited by: V. Kotroni and K. Lagouvardos

Reviewed by: anonymous referee

\section{References}

Avissar, R. and Pielke, R. A.: A parameterization of heterogeneous land surfaces for atmospheric numerical models and its impact on regional meteorology, Mon. Wea. Rev., 117, 10, 2113-2136, 1989.

Dai, Y. J. and Co-authors: The Common Land Model, Bull. Amer. Meteorol. Soc., 84, 8, 1013-1023, 2003.

Dinku, T. and Anagnostou, E. N.: Regional Differences in Overland Rainfall Estimation from PR-Calibrated TMI Algorithm, J. Appl. Meteorol., 44, 2, 189-205, 2005a.

Dinku, T. and Anagnostou, E. N.: TRMM Calibration of SSM/I Algorithm for Overland Rainfall Estimation, J. Appl. Meteorol., accepted, 2005b.

Eltahir, E. A. B. and Bras, R. L.: Estimation of the fractional coverage of rainfall in climate models, J. Climate, 6, 4, 639-644, 1993.

Ghan, S. J., Liljigren, J. C., Shaw, W. J., Hubbe, J. H., and Dorman, J. C.: Influence of subgrid variability on surface hydrology, J. Clim., 10, 12, 3157-3166, 1997.

Grecu, M. and Anagnostou, E. N.: Use of passive microwave observations in a radar rainfall profiling algorithm, J. Appl. Meteorol., 41, 7, 702-715, 2002.

Kalnay, E. and Co-authors: The NCEP/NCAR 40-year analysis project, Bull. Amer. Meteorol. Soc., 77, 3, 437-471, 1996.

Kummerow, C. and Co-authors: The Status of the Tropical Rainfall Measuring Mission (TRMM) after Two Years in Orbit, J. Appl. Meteorol., 39, 12, 1965-1982, 2000.

Llorens, P., Poch, R., Latron, J., and Gallart, F.: Rainfall interception by a Pinus sylvestris forest patch overgrown in a Mediterranean mountainous abandoned area. I. Monitoring design and results down to the event scale: J. Hydrol., 199, 331-345, 1997.

Shuttleworth, W. J.: Macrohydrology-The new challenge for process hydrology, J. Hydrol., 100, 1-3, 31-56, 1988.

Tian, Y., Dickinson, R. E., Zhou, L., Zeng, X., Dai, Y., Myneni, R. B., Knyazikhin, Y., Zhang, X., Friedl, M., Yu, H., Wu, W., and Shaikh, M.: Comparison of seasonal and spatial variations of LAI/FPAR from MODIS and Common Land Model, J. Geophys. Res., 109, D01103, doi:10.1029/2003JD003777, 2004.

Wang, D., Wang, G., and Anagnostou, E. N.: Use of satellite-based precipitation observation in improving the parameterization of canopy hydrological processes in land surface models, J. Hydrometeorol., 6, 5, 745-763, 2005.

Wang, G. L. and Eltahir, E. A. B.: Impact of rainfall sub-grid variability on modeling the biosphere-atmosphere system, J. Climate, 13, 16, 2887-2899, 2000. 